Tạp chí Khoa học và Công nghệ biển T10 (2010). Số 1. Tr 37 - 49

\title{
CHẾ TẠO THIẾT BỊ ĐÁNH GIÁ NHANH CHẤT LỰ̛̣G MÔI TRƯỜNG NƯỚC BIỂN VEN BỜ
}

\author{
NGUYẼ̃N THÀNH ĐÚC, NGUYẼ̃N MINH TRÚC, LÊ THÀNH DŨNG, VŨ TRỌNG HÙNG \\ Trường Đại học Khoa học Tự nhiên, Thành phố Hồ Chí Minh
}

\begin{abstract}
Tóm tắt: Ô nhiễm môi truờng đã và đang là một thực trạng báo động ở Việt Nam. Một trong nhũng nguyên nhân là sự hạn chế về trang bị kỹ thuật giúp đánh giá nhanh hiện trạng môi truờng. Kết quả đánh giá môi truờng tại chỗ sẽ giúp các nhà quản lý cũng nhu nguời dân có nhũng định huớng và giải pháp phù hợp. Dựa trên mục tiêu này, nhóm nghiên cứu chúng tôi đã phát triển thiết bị đo quang phổ hấp thu cầm tay và bộ hóa chất để xác định nhanh 3 chỉ tiêu dinh duõng trong môi truờng nuơóc biển gồm nitrit $\left(\mathrm{NO}_{2}{ }^{-}\right)$, amoni $\left(\mathrm{NH}_{4}^{+}\right)$và photphat $\left(\mathrm{PO}_{4}{ }^{3-}\right)$. Thủ nghiệm cho thấy, máy quang phổ hấp thu cầm tay và bộ thuốc thư đạt giới hạn

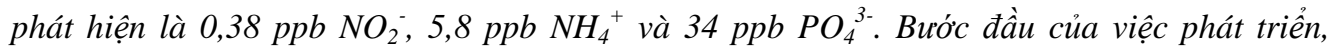
nhóm nghiên cứu đã thành công trong việc chế tạo thiết bị cầm tay và bộ hóa chất làm việc tốt trong điều kiện của Việt Nam, thuận tiện cho việc đo đạt ngoài môi truờng, chất luợng đảm bảo khi so sánh với bộ kit nhập khẩu, dễ dàng chế tạo, giá thành thấp, phù hợp với thị truờng của Việt Nam nên có thể cung cấp rộng rãi cho cộng đồng.
\end{abstract}

\section{MỞ ĐẦU}

Khoa học kỹ thuật của Thế giới đã phát triển mạnh mẽ lĩnh vực công nghệ chế tạo các thiết bị đánh giá chất lượng môi trường tự nhiên $[1,5]$. Nhu cầu quản lý môi trường đòi hỏi phải nghiên cứu, thiết kế chế tạo các thiết bị xác định nhanh, chuẩn mực chất lượng môi trường nhằm đảm bảo sức khỏe cho người dân và hiệu quả trong phát triển kinh tế, đặc biệt là trong lĩnh vực nghề cá, nuôi trồng thủy hải sản, du lịch, nghỉ dưỡng ven biển [1]. Tuy nhiên, thực tế áp dụng các chuẩn mực quản lý trong đo đạc, phân tích, đánh giá định lượng chất lượng môi trường biển ở Việt Nam gặp rất nhiều khó khăn do hạn chế về kiến thức, kỹ thuật cũng như trang thiết bị cho cộng đồng. Căn cứ vào nhu cầu bức xúc của thực tế phát triển các ngành kinh tế, xã hội ven biển, cũng như khả năng và điều kiện thực tiễn của Việt Nam, chúng tôi mạnh dạn đặt ra nhiệm vụ nghiên cứu, chế tạo một thiết bị đơn giản, rẻ tiền nhưng vẫn đáp ứng được các tiêu chuẩn kỹ thuật, độ chuẩn xác hóa học để xác định một số chỉ tiêu quan trọng trong môi trường nước biển. Trước mắt,với sự khuyến khích và tài trợ tài chính của đề tài cấp Nhà nước KC 09-07, tập thể tác giả đã tiến hành nghiên cứu chế tạo bộ "kít “ xác định nhanh, chính xác 3 anion $\mathrm{NO}_{2}{ }^{-}, \mathrm{NH}_{4}{ }^{+}, \mathrm{PO}_{4}{ }^{3-}$ 
trong nước biển. Hiện nay, các công ty hóa chất và thiết bị lớn trên Thế giới cũng đã chế tạo nhiều loại bộ "kit" nhằm đánh giá bán định lượng các chất khác nhau phục vụ trong các ngành vệ sinh, y tế công cộng, môi trường... Các bộ "kit" này đang được bán rộng rãi tại Việt Nam với giá thành cao do phải phụ thuộc vào nguồn hóa chất phụ trợ nhập khẩu. Mục đích của nhóm tác giả là mong muốn và chứng minh khả năng chế tạo đạt tiêu chuẩn và độ chính xác cho phép qua việc phân tích đối chiếu và so sánh với các thiết bị tương tự nhập khẩu các bộ "kit" tương tự đi kèm thiết bị đo độ hấp thụ quang nhỏ gọn, tiện dụng cho nhiều mục tiêu của thực tế và thuận tiện cho việc đo đạc ngoài thực địa, giá thành thấp, phù hợp với thị trường của Việt Nam nên có thể cung cấp rộng rãi cho cộng đồng.

Bài báo này công bố các kết quả nghiên cứu, thiết kế và chế tạo thiết bị đo nhanh 3 anion $\mathrm{NO}_{2}{ }^{-}, \mathrm{NH}_{4}{ }^{+}, \mathrm{PO}_{4}{ }^{3-}$ trong nước biển và các kết quả ứng dụng đo đạc thực tế tại vùng biển Vũng Tàu, Phan Thiết với kết quả so sánh đối chứng trên các thiết bị nhập khẩu của hãng như SHIMADZU 10-UV; SECONMAN S570.

\section{Các nguyên lý khoa học cơ bản}

Các nguyên lý khoa học cơ bản của việc thiết kế thiết bị đo nhanh 3 anion $\mathrm{NO}_{2}{ }^{-}$, $\mathrm{NH}_{4}{ }^{+}, \mathrm{PO}_{4}{ }^{3-}$ đã được giới thiệu kỹ trong công trình [3].

Nguyên nhân chính sản sinh $\mathrm{ra} \mathrm{NO}_{2}^{-}$trong tự nhiên bắt nguồn từ động thực vật. Protein của động thực vật bị phân hủy bởi nhiều loại vi sinh vật và được chuyển hóa thành các acid amin tự do, sau đó là sự khử các amin để giải phóng $\mathrm{NH}_{4}{ }^{+}$và $\mathrm{NH}_{3}$.

$$
\mathrm{CO}\left(\mathrm{NH}_{2}\right)_{2}+2 \mathrm{H}_{2} \mathrm{O} \stackrel{\text { Urease }}{\longrightarrow} \mathrm{NH}_{4}^{+}+\mathrm{NH}_{3}+\mathrm{HCO}_{3}^{-}
$$

Trong môi trường tồn tại loại vi khuẩn nitrosomonas, có khả năng dự trữ năng lượng bằng cách oxit hóa $\mathrm{NH}_{4}{ }^{+}$thành $\mathrm{NO}_{2}{ }^{-}$:

$$
\mathrm{NH}_{4}^{+}+1.5 \mathrm{O}_{2} \stackrel{\text { Nitrosomonas }}{\longrightarrow} \mathrm{NO}_{2}^{-}+\mathrm{H}_{2} \mathrm{O}+2 \mathrm{H}^{+}
$$

Mặt khác vi khuẩn nitrosomonas có thể oxit hóa $\mathrm{NH}_{2} \mathrm{OH}$ thành $\mathrm{NH}_{3}$ và $\mathrm{NO}_{2}^{-}$. Nhiều hợp chất chứa nitơ hòa tan trong nước đã dẫn tới sự tăng nồng độ các hợp chất nitơ trong nước bề mặt. Trước hết là urê, sản phẩm của quá trình urê hóa trong tự nhiên và phân bón, sau đó là amoniac và muối amoni từ phân bón, từ quá trình thối rữa từ chu trình dinh dưỡng sinh học cũng như từ nước thải sinh hoạt, nông nghiệp và công nghiệp. Nitrit là kết quả của quá trình thoái hóa các hợp chất hữu cơ có chứa gốc $\mathrm{N}$ trong chu trình nitrogen. Trong môi trường kị khí với sự có mặt của chất cho hydro hữu cơ xảy ra sự khử dị hóa nitrat sang nitrit. Trong đa số trường hợp, nhiều vi sinh vật khử nitrat thành nitrit hơn là khử trực tiếp nitrit thành nitơ tự do. 
Nitrit trong nước phần lớn do sự chuyển hóa các chất hữu cơ dưới tác dụng của vi sinh vật. Hiện nay một lượng vô cùng lớn phân bón nitơ được con người sử dụng để phát triển nông nghiệp. Chính lượng phân bón này đã bổ sung nhiều hợp chất chứa $\mathrm{N}$ dưới dạng $\mathrm{NO}_{3}{ }^{-}$tiêu thụ nhanh trong đất. Đây cũng là nguồn sinh ra bởi các quá trình sinh học. Các phân bón này có độ tan rất lớn trong nước do đó dễ dàng gây ô nhiễm nguồn nước ngầm và nước bề mặt. Hàm lượng nitrit trong các dòng sông ngày càng tăng chứng tỏ việc tổn thất nitơ từ phân bón trên đồng ruộng ngày càng lớn. Theo ước tính hàng năm có khoảng 30.000 tấn nitơ được vận chuyển ra biển dưới dạng nitrat và nitrit.

Trong nuớc sông hàm lượng nitrit rất thấp, chỉ khoảng 0.01 ppm, chỉ khi nước sông bị ô nhiễm mới có thể tăng lên $0.05 \mathrm{ppm}$. Nếu như nước chứa chủ yếu Nitơ ở dạng $\mathrm{NO}_{2}^{-}$ thì nước đó đã bị ô nhiểm trong một thời gian dài.

Amoniac xuất hiện trong các khu đầm lầy có chứa nhiều chất mùn mục, vì chất mùn có thể làm cho gốc $\mathrm{NO}_{3}{ }^{-}$bị khử thành $\mathrm{NH}_{4}{ }^{+}$. Ngoài ra, ion $\mathrm{NH}_{4}{ }^{+}$còn là thành phần chính của các sản phẩm công nghiệp như đạm, thuộc da,... Sự tồn tại của $\mathrm{NH}_{3}$ là yếu tố để đánh giá mức độ nhiễm bẩn của nước bề mặt, nước biển, nước ngầm, ở các vùng lân cận thành phố và các khu công nghiệp. Ion $\mathrm{NH}_{4}{ }^{+}$tương đối không ổn định, dưới tác dụng của các yếu tố hóa học, vật lý và sinh học nó chuyển hóa thành các hợp chất khác của $\mathrm{N}$. Amoni tồn tại trong nước ở hai dạng $\mathrm{NH}_{3}$ và $\mathrm{NH}_{4}{ }^{+}$, tỷ lệ $\mathrm{NH}_{3} / \mathrm{NH}_{4}{ }^{+}$tùy thuộc vào $\mathrm{pH}$ của nước (khi nói amoni là chỉ chung cả hai dạng trên).

Phospho tồn tại trong nước chủ yếu dưới dạng phosphat, là kết quả của các quá trình phong hóa, bào mòn đất đá, hoặc do chính tác động của con người. Phosphat lại có thể phân loại thành ba dạng:

\section{Phospho hũu co:}

Là các dẫn xuất hữu cơ của acid phosphoric như DNA, RNA (các vật chất di truyền), ATP (dự trữ và cung cấp năng lượng cho hoạt động của tế bào), hay các phospholipid.

Trong môi trường nước tự nhiên, phospho hữu cơ thường nằm trong pha lơ lửng, trong xác các phiêu sinh vật, xác động thực vật chưa phân hủy. Tuy nhiên, chúng sẽ dần dần bị các vi sinh vật phân hủy chuyển về dạng vô cơ.

\section{Polyphosphat:}

Là dạng tụ hợp của orthophosphat thường không bền và dễ chuyển hóa thành các phosphat đơn. Polyphosphat tạo được phức với nhiều kim loại, có ứng dụng rộng rãi trong các ngành công nghiệp chống ăn mòn và xử lý nước. 


\section{Orthophosphat:}

Là dạng bền nhất của phospho trong tự nhiên, được tạo thành từ quá trình phong hóa bào mòn đất đá. Phospho trong đất đá dần dần được phóng thích dưới dạng ion phosphat vào môi trường nước.

Orthophosphat trong đất thường bị các hạt keo giữ chặt, nhờ quá trình trao đổi ion xảy ra trên bề mặt rễ, orthophosphat được cây hấp thụ làm thức ăn. Một số loại tảo sử dụng orthophosphat làm thức ăn, do vậy hàm lượng phosphat trong nước bề mặt thường không cao. Tuy nhiên do các hoạt động trực tiếp hoặc gián tiếp từ con người, hàm lượng orthophosphat có thể cao bất thường. Nước thải sinh hoạt thường chứa lượng lớn các chất tẩy rửa có nguồn gốc từ polyphosphat, chất này bị thủy phân thành các orthophosphat. Các hoạt động sản xuất nông nghiệp của con người cũng thải vào môi trường các loại phosphat qua phân bón, các chất này bị nước mưa rửa trôi vào sông hồ và ra biển.

\section{Thiết bị và phương pháp}

\subsection{Chế tạo thiết bị xác định Phosphat và Nitơ, phiên bản PN01}

Về cơ bản, máy quang phổ hấp thu, phiên bản PN01 có cấu tạo cũng như hoạt động tương tự như các máy quang phổ hấp thu phân tử khác. Tuy nhiên, với mục tiêu đề ra là chế tạo được máy quang phổ hấp thu phân tử nhỏ gọn, tiện lợi khi di chuyển và hoạt động ổn định, nên máy PN01 có thiết kế, cấu tạo theo nguyên tắc của máy quang phổ 2 kênh. Máy PN01 đo cùng lúc ánh sáng từ nguồn qua kênh tham khảo (reference) và kênh mẫu (sample), (hình 1). Theo nguyên tắc này thì máy PN01 sẽ có tính ổn định cao.

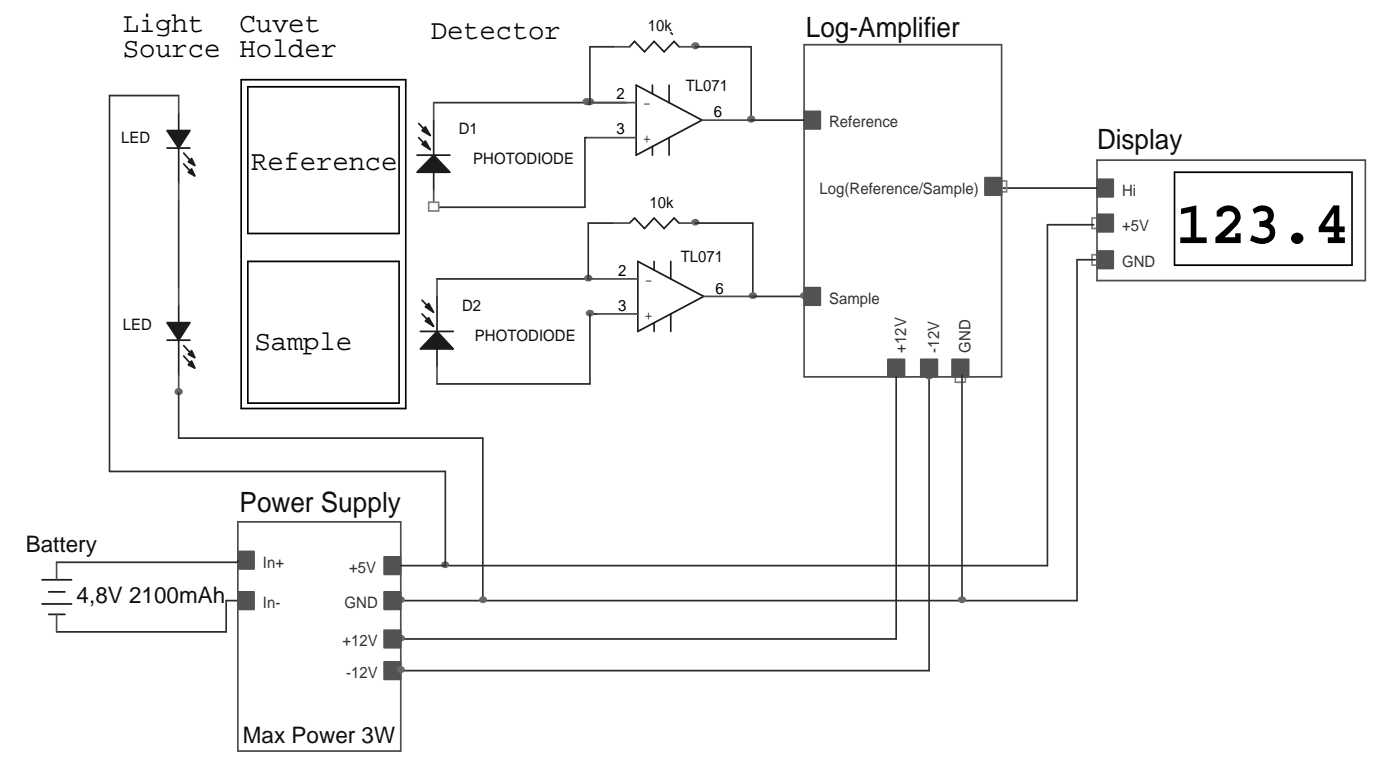

Hình 1: Sơ đồ mạch nguyên tắc hoạt động của máy PN01 
Máy quang phổ hấp thu phân tử PN01 là loại máy quang phổ 2 kênh. Gồm 6 phần chính (hình 1):

1. Nguồn điện (Power supply): Cung cấp điện áp ổn định để nuôi hệ thống.

2. Nguồn sáng PN01 (Light source): Cung cấp bức xạ đơn sắc.

3. Hộc cuvet (Cuvet holder): chuyên dùng cho cuvet $1 \mathrm{~cm}$.

4. Đầu đo (detector): Chuyển đổi tín hiệu quang thành tín hiệu điện.

5. Mạch xử lý tín hiệu (log-amplifier): Khuếch đại tín hiệu sơ cấp, và chuyển đổi thành tín hiệu độ hấp thu.

6. Bộ hiện số (display): hiển thị giá trị độ hấp thu.

Do yêu cầu phải nhỏ gọn, dễ dàng di chuyển, nên nguồn phát xạ ánh sáng của máy PN01 không dùng đèn phát phổ rộng và bộ đơn sắc như các máy quang phổ hấp thu thông thường mà ở đây nó dùng một LED phát quang phát ra bức xạ ánh sáng có vùng phổ hẹp ứng với bước sóng cần. Để xác định nitrite (phức màu azo đo tại bước sóng $540 \mathrm{~nm}$ ), dùng đèn led phát ánh sáng màu xanh lá cây $(526 \mathrm{~nm}$ ); xác định amoni (phức màu indophenol đo tại bước sóng $635 \mathrm{~nm}$ ), chúng tôi dùng đèn led phát bức xạ màu đỏ (650 - $760 \mathrm{~nm}$ ); với phosphate (phức dị đa phospho molybdate có hai mũi hấp thu tại $700 \mathrm{~nm}$ và $880 \mathrm{~nm}$ ), để đạt được độ nhạy cao thì phải đo tại bước sóng $880 \mathrm{~nm}$ bằng đèn led IR. Tuy nhiên do hạn chế về mặt linh kiện của công tắc chuyển và đầu dò, nên ở đây chúng tôi chọn sử dụng đèn led phát ánh sáng màu đỏ chung với đèn led để đo amoni.

Với việc sử dụng đèn led phát bức xạ ánh sáng có vùng phổ hẹp tương ứng cần thiết giúp làm giảm giá thành sản phẩm, dễ dàng thay thế và sử dụng. Ngoài ra, do đèn led là loại đèn có công suất tiêu thụ năng lượng thấp $(0,15-0,4 \mathrm{~W})$, hệ số phản hồi cao, nhanh ổn định nên sẽ không phải chờ đèn ổn định và tiết kiệm điện. Tiện lợi thứ hai là các loại đèn led phát bức xạ ánh sáng màu hiện đang được sử dụng rộng rãi cho mục đích trang trí... nên dễ dàng mua mới và thay thế tại Việt Nam.

Chi tiết quan trọng kế tiếp trong máy quang phổ hấp thu là đầu dò. Ở đây, chúng tôi sử dụng diode quang, là linh kiện chuyển đổi tuyến tính tín hiệu quang thành tín hiệu điện. Ưu điểm của loại diode quang này là chúng rất nhạy sáng và bền trong điều kiện nhiệt đới.

Tín hiệu điện sau khi ra khỏi đầu đo, sẽ được khuếch đại bằng IC op-am TL071 trước khi đi vào mạch xử lý tín hiệu. Trong mạch xử lý tín hiệu, năng lượng truyền quang sẽ được xử lý và chuyển đổi thành độ hấp thu bằng ic LM 394. Ưu điểm của ic này là ít nhiễu, độ ổn định cao, khoảng tuyến tính rộng. Tuy nhiên, nhược điểm của nó là hệ số chuyển đổi log thập phân thường khác 1 do ic này hoạt động phụ thuộc nhiều vào các linh kiện phụ trợ bên 
ngoài. Trong định hướng cải tiến, chúng tôi quyết định thay thế ic LM 394 bằng ic ICL 8048. Tuy nhiên, do hạn chế về mặt thời gian nên ic 8048 vẫn chưa được chạy thử.

Dựa trên các thiết bị sử dụng, mạch cấp nguồn được thiết kế để đảm bảo cung cấp điện áp đủ và ổn định. Máy PN01 được thiết kế để sử dụng 2 loại nguồn là adapter cắm điện $(9 \mathrm{~V})$ và pin (4 pin $\mathrm{AA} 2100 \mathrm{mAh})$. Khi sử dụng máy để đo trong phòng thí nghiệm hay ở nơi có nguồn $\mathrm{AC} 220 \mathrm{~V}$, có thể sử dụng nguồn cắm adapter $\mathrm{DC} 9 \mathrm{~V}$ bằng cách gạt nút chỉnh nguồn về vị trí $220 \mathrm{~V}$. Nếu sử dụng khi đi thực địa hay ở những nơi không có điện thì sử dụng pin có thể xạc lại, loại AA $2100 \mathrm{mAh}$, với pin này thì thời gian sử dụng sẽ là 8 giờ.

\subsection{Tối ưu hóa thực nghiệm quy trình xác định amoni trong nước biển}

Quá trình tối ưu hóa quy trình xác định amoni trong nước biển được thực nghiệm theo các tài liệu đã được công bố $[2,4,5,6]$.

- Hóa chất:

+ Phenol: $10 \mathrm{~g}$ phenol/100 $\mathrm{ml} \mathrm{C}_{2} \mathrm{H}_{5} \mathrm{OH}$.

+ Natri nitroprusside: $0.5 \mathrm{~g}$ natri nitroprusside/100 $\mathrm{ml} \mathrm{H}_{2} \mathrm{O}$ cất.

+ Natri citrate: hòa tan $200 \mathrm{~g}$ Natri Citrate $+24 \mathrm{~g} \mathrm{NaOH}$ trong $\mathrm{H}_{2} \mathrm{O}$ thành $1000 \mathrm{~mL}$

- Cách pha chế:

Dung dịch PP: $50 \mathrm{~mL}$ Phenol + $37.5 \mathrm{~mL}$ Natri nitroprusside.

Dung dịch OX: 100 mL dung dịch Natri citrate + với 25 mL NaOCl 5,5\%.

- Lên màu trên cuvet

- Lấy khoảng $5 \mathrm{~mL}$ mẫu nước, lọc qua giấy lọc $0.45 \mu \mathrm{m}$.

- Sử dụng xy lanh y tế: Hút chính xác $2.75 \mathrm{~mL}$ mẫu nước qua lọc vào cuvet, thêm 90 $\mu \mathrm{L}$ thuốc thử $\mathrm{PP}$ và $160 \mu \mathrm{L}$ thuốc thử $\mathrm{OX}$

- Sau 60 phút, đem đo độ hấp thu trên máy PN01 (chỉnh chế độ đo amoni) với dung dịch so sánh là nước cất và hỗn hợp thuốc thử.

\subsection{Tối ưu hóa thực nghiệm quy trình xác định nitrit trong nước biển}

Quá trình tối ưu hóa quy trình xác định nitrit trong nước biển đã được thực nghiệm theo các tài liệu đã được công bố trong $[2,4,6,7]$.

- Hóa chất

+ Nước cất 
+ Dung dịch $\mathrm{H}_{3} \mathrm{PO}_{4}$ đậm đặc $(85 \%)$

+ Sulfanylamide

+ Dung dịch N-(1-naphthyl)-ethylene dihydrochloride (NED.2HCl):

+ Dung dịch chuẩn nitrite gốc 250 ppm N: hòa tan $1.232 \mathrm{~g} \mathrm{NaNO}_{2}$ trong nước cất thành $1000 \mathrm{~mL}$. Thêm $1 \mathrm{~mL} \mathrm{CHCl}_{3}$ để bảo quản. Dung dịch giữ lạnh có thể sử dụng trong 1 tháng.

Dung dịch chuẩn làm việc 250 ppb $N$ : hút chính xác $1 \mathrm{~mL}$ dung dịch nitrite gốc, định mức bằng nước cất thành $1000 \mathrm{~mL}$, dung dịch sử dụng trong ngày.

- Cách pha chế:

Thuốc ithư SFA: hòa tan $1 \mathrm{~g}$ sulfanylamide trong $70 \mathrm{~mL} \mathrm{H}_{3} \mathrm{PO}_{4}$ đậm đặc và nước cất thành $100 \mathrm{~mL}$. Dung dịch bền trong một tháng nếu được bảo quản trong bình tối màu.

Thuốc thử NED: hòa tan $0.07 \mathrm{~g} \mathrm{NED.2HCl} \mathrm{trong} \mathrm{nước} \mathrm{cất} \mathrm{thành} 100 \mathrm{~mL}$. Dung dịch bền trong một tháng nếu được bảo quản lạnh trong bình tối màu.

- Lên màu trên cuvet

- Lấy $5 \mathrm{~mL}$ mẫu nước, lọc qua giấy lọc $0.45 \mu \mathrm{m}$.

- Hút chính xác $3 \mathrm{~mL}$ mẫu nước qua lọc vào cuvet, thêm $150 \mu \mathrm{L}$ thuốc thử $S F A$ và $100 \mu \mathrm{L}$ thuốc thử $N E D$.

- Sau 5 phút, đem đo độ hấp thu trên máy PN01 (chỉnh chế độ đo nitrite) với dung dịch so sánh là nước cất và hỗn hợp thuốc thử.

\subsection{Tối ưu hóa thực nghiệm quy trình xác định photphat trong nước biển}

- Hóa chất

+ Nước cất 2 lần

+ Dung dịch $\mathrm{H}_{2} \mathrm{SO}_{4}$ đậm đặc

+ Dung dịch amoni molypdate gốc 10000 ppm Mo: cân 9.2017g $(\mathrm{NH} 4)_{6} \mathrm{Mo}_{7} \mathrm{O}_{24} \cdot 4 \mathrm{H}_{2} \mathrm{O}$ pha trong $500 \mathrm{~mL}$ nước cất.

+ Dung dịch kali antimonyl tartrat gốc 1000 ppm Sb: cân $1.3720 \mathrm{~g}$ $\mathrm{K}(\mathrm{SbO}) \mathrm{C}_{4} \mathrm{H}_{4} \mathrm{O}_{6} \cdot 1 / 2 \mathrm{H}_{2}$ Opha trong $500 \mathrm{~mL}$ nước cất.

+ Dung dịch axit ascorbic gốc 10000 ppm: cân 2.5 g L-Ascorbic axit pha trong 250 $\mathrm{mL}$ nước cất, dung dịch có thể sử dụng trong vòng một tuần ở nhiệt độ phòng.

+ Dung dịch chuẩn phosphate gốc 1000 ppm $\mathrm{PO}_{4}{ }^{3-}$ : cân $0.6877 \mathrm{~g}\left(\mathrm{NH}_{4}\right)_{2} \mathrm{HPO}_{4}$ pha 
trong $500 \mathrm{~mL}$ nước cất.

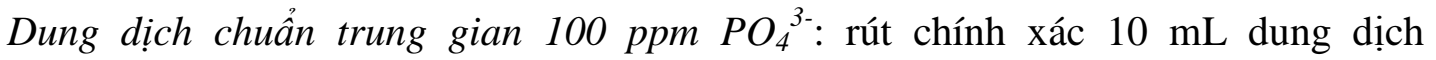
phosphate gốc, định mức bằng nước cất đến $100 \mathrm{~mL}$.

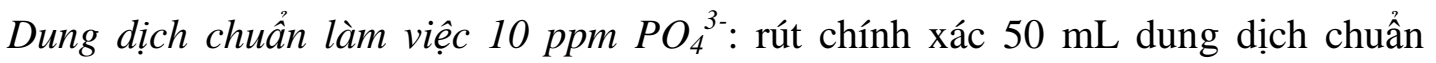
trung gian, định mức bằng nước cất đến $500 \mathrm{~mL}$.

- Pha hỗn hợp thuốc thử

Cho vào bình định mức $250 \mathrm{~mL}$ : $100 \mathrm{~mL}$ nước cất, $17.2 \mathrm{~mL}$ dung dịch $\mathrm{H}_{2} \mathrm{SO}_{4}$ đậm đặc, để nguội. Thêm tiếp $62.5 \mathrm{~mL}$ dung dịch amoni molypdate gốc, $25 \mathrm{~mL}$ dung dịch kali antimonyl tartrat gốc và $125 \mathrm{~mL}$ dung dịch axit ascorbic gốc. Định mức bằng nước cất.

Hỗn hợp thuốc thử có màu vàng nhạt, ổn định trong 4 h.

- Lên màu trên cuvet

- Lấy $5 \mathrm{~mL}$ mẫu nước, lọc qua giấy lọc $0.45 \mu \mathrm{m}$.

- Hút chính xác $3.6 \mathrm{~mL}$ mẫu nước qua lọc vào cuvet, thêm $0.4 \mathrm{~mL}$ thuốc thử.

- Sau 10 phút, đem đo độ hấp thu trên máy PN01 (chỉnh chế độ đo phosphate) với dung dịch so sánh là nước cất và hỗn hợp thuốc thử.

\section{Khảo sát các quy trình phân tích bằng máy PN01 trong thực tiễn}

Nội dung khảo sát bao gồm nghiên cứu các thông số như độ nhạy của máy so sánh với một máy quang phổ UV - VIS, độ lặp lại của đường chuẩn, phương sai tái hiện so sánh với một máy quang phổ UV - VIS khác.

\subsection{Phân tích amoni}

So sánh giới hạn phát hiện và giới hạn định lượng với máy SHIMADZU 10-UV:

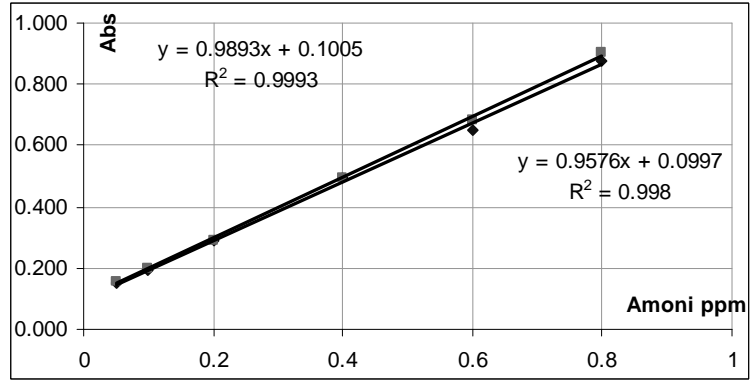

Hình 2: Độ lặp lại của đường chuẩn quy trình phân tích amoni trên máy PN01 đo cách nhau 8 giờ

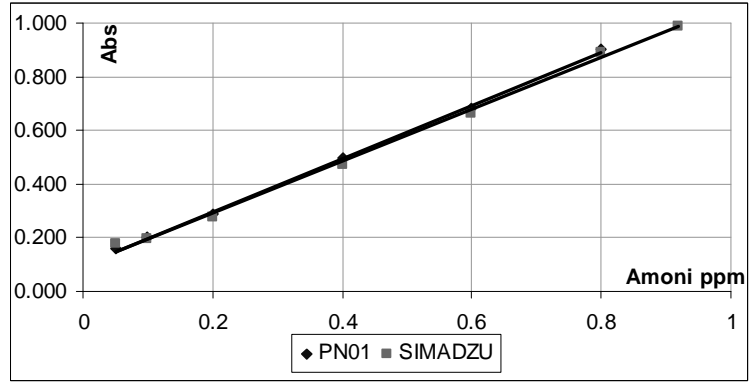

Hình 3: So sánh dãy chuẩn với máy SHIMADZU 10-UV 
Bảng 1: So sánh các thông số giữa hai máy trong quy trình phân tích amoni

\begin{tabular}{|c|c|c|}
\hline Các giá trị so sánh & Máy PN01 & Máy SHIMADZU 10-UV \\
\hline LOD ppm NH$_{3}$ & 0,0058 & 0,00621 \\
\hline LOQ ppm NH & 0,0204 \\
\hline \multirow{2}{*}{ Phương trình đường chuẩn } & $\begin{array}{c}0,019 \\
0,9893 x+0,1005 \\
R^{2}=0,9993\end{array}$ & $\begin{array}{c}Y=0,9612 x+0,102 \\
R^{2}=0,9974\end{array}$ \\
\hline Phương sai tái hiện & 0,000209 & 0,000227 \\
\hline
\end{tabular}

Vậy trong quy trình phân tích amoni, hai máy có độ chính xác tương đương nhau. Máy PNO1 có phần nhạy hơn và độ tuyến tính cao hơn.

\subsection{Phân tích Nitrit}

So sánh giới hạn phát hiện và giới hạn định lượng với máy SHIMADZU 10-UV:

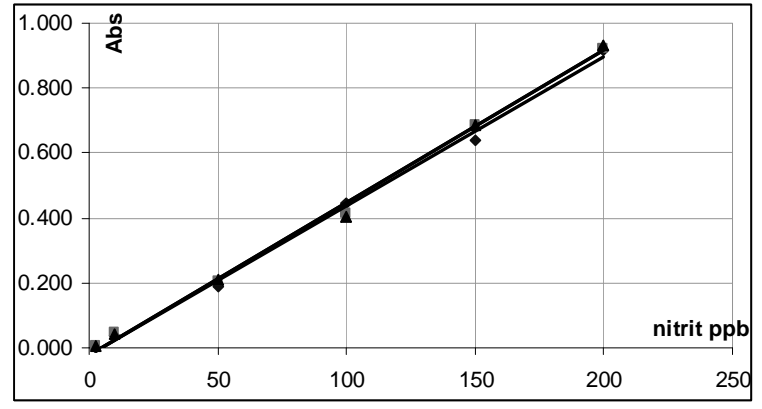

Hình 4: Độ lặp lại của đường chuẩn quy trình nitrit trên máy PN01

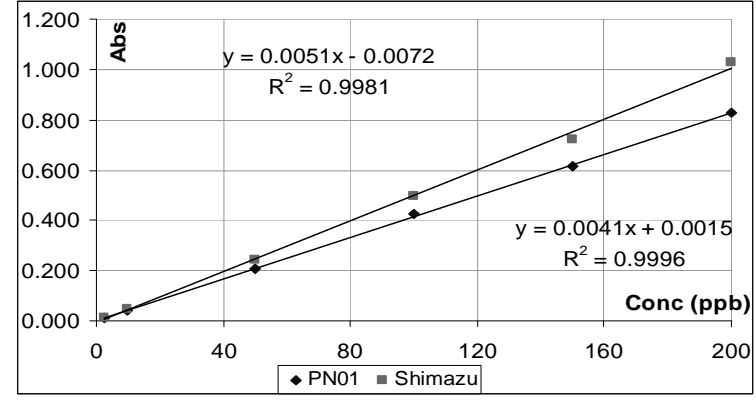

Hình 5: So sánh đường chuẩn của quy trình nitrit giữa máy PN01 và máy SHIMADZU 10-UV

Bảng 2: So sánh các thông số phân tích của quy trình phân tích nitrit giữa máy PN01 và máy SHIMADZU 10-UV

\begin{tabular}{|c|c|c|}
\hline Các giá trị so sánh & Máy PN01 & Máy SHIMADZU 10-UV \\
\hline LOD ppb $\mathrm{NO}_{2}$ & 0,38 & 0,57 \\
\hline LOQ ppb NO & 1,26 & 1,90 \\
\hline Phương trình đường chuẩn & $\begin{array}{c}Y=0,0041 x+0,0015 \\
R^{2}=0,9996\end{array}$ & $\begin{array}{c}Y=0,0051 x-0,0072 \\
R^{2}=0,9981\end{array}$ \\
\hline Phương sai tái hiện & $4,33 * 10^{-6}$ & $4,33 * 10^{-6}$ \\
\hline
\end{tabular}


Trong quy trình phân tích nitrit, máy PNO1 có độ tuyến tính và độ nhạy tốt hơn. Giới hạn định lượng như vậy bảo đảm để xác định chỉ tiêu nitrit trong nước bề mặt.

\subsection{Phân tích Phosphat}

So sánh giới hạn phát hiện và giới hạn định lượng với máy SECONMAN S570:

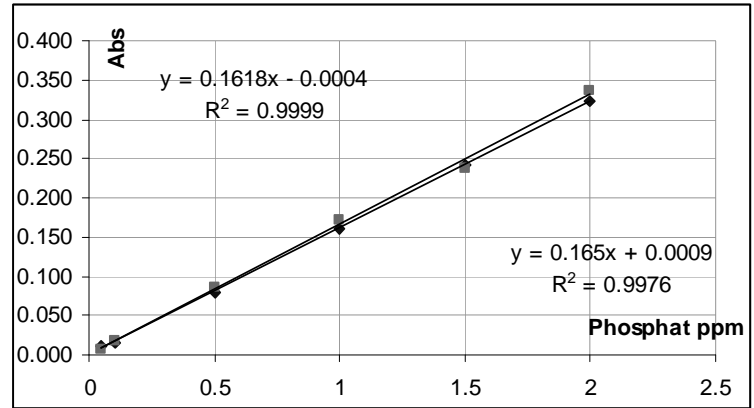

Hình 6: Độ lặp lại của đường chuẩn trong quy trình phân tích phosphat trên máy PN01

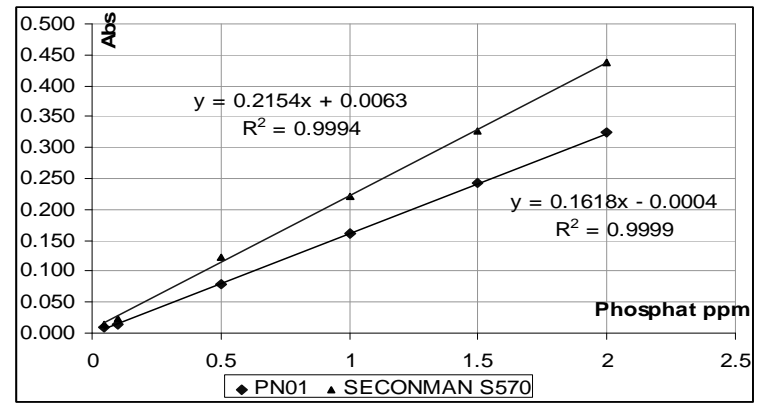

Hình 7: So sánh đường chuẩn quy trình phân tích phosphat giữa máy PN01 và máy SECONMAN S570

Bảng 3: So sánh các thông số giữa hai máy trong quy trình phân tích phosphat

\begin{tabular}{|c|c|c|}
\hline Các giá trị so sánh & Máy PN01 & Máy SECONMAN S570 \\
\hline LOD ppm $\mathrm{PO}_{4}{ }^{3-}$ & 0,034 & 0,008 \\
\hline LOQ ppm $\mathrm{PO}_{4}{ }^{3-}$ & 0,112 & 0,027 \\
\hline $\begin{array}{c}\text { Phương trình đường } \\
\text { chuẩn }\end{array}$ & $Y=0,1618 x-0,0004$ & $Y=0,02154 x+0,0063$ \\
$R^{2}=0,9999$ & $R^{2}=0,9994$ \\
\hline Phương sai tái hiện & $3,00 * 10^{-7}$ & $1,00 * 10^{-6}$ \\
\hline
\end{tabular}

Trong quy trình phân tích phosphat, độ nhạy của máy PN01 thấp hơn máy SECONMAN S570 vẫn bảo đảm để xác định hàm lượng phosphat trong nước tự nhiên.

\subsection{Phân tích mẫu thực tế}

Sau khi khảo sát các thông số trên, chúng tôi tiến hành làm kiểm tra chéo giữa các phòng thí nghiệm. Sử dụng máy PNO1 để đo trực tiếp ngoài hiện trường tại bờ biển Phan Thiết và Vũng Tàu, mẫu được lấy theo TCVN 6663 - 13: 2000 và đem về phân tích tại phòng thí nghiệm phân tích thuộc Bộ môn Hóa phân tích Trường Đại học Khoa học Tự nhiên thực hiện. 
Bảng 4: So sánh kết quả phân tích thực tế giữa máy PN01 và Phòng thí nghiệm

\begin{tabular}{|l|c|c|c|l|l|c|}
\hline \multirow{2}{*}{$\begin{array}{l}\text { Địa điếm } \\
\text { Lấy mâu }\end{array}$} & \multicolumn{2}{|c|}{ Amoni ppm } & \multicolumn{2}{c|}{ Nitrit ppb } & \multicolumn{2}{c|}{ Phosphat ppm } \\
\cline { 2 - 7 } & Máy PN01 & PTN HPT & Máy PN01 & & Máy PN01 & PTN HPT \\
\hline $\begin{array}{l}\text { Vũng } \\
\text { Tàu }\end{array}$ & $\begin{array}{c}\text { Không } \\
\text { phát hiện }\end{array}$ & $\begin{array}{c}\text { Không } \\
\text { phát hiện }\end{array}$ & 10.52 & $\begin{array}{l}\text { Vũng } \\
\text { Tàu }\end{array}$ & $\begin{array}{c}\text { Không } \\
\text { phát hiện }\end{array}$ & $\begin{array}{c}\text { Không } \\
\text { phát hiện }\end{array}$ \\
\hline $\begin{array}{l}\text { Phan } \\
\text { Thiết }\end{array}$ & $\begin{array}{c}\text { Không } \\
\text { phát hiện }\end{array}$ & $\begin{array}{c}\text { Không } \\
\text { phát hiện }\end{array}$ & 4.83 & $\begin{array}{l}\text { Phan } \\
\text { Thiết }\end{array}$ & $\begin{array}{c}\text { Không } \\
\text { phát hiện }\end{array}$ & $\begin{array}{c}\text { Không } \\
\text { phát hiện }\end{array}$ \\
\hline
\end{tabular}

\section{KẾT LUẬN}

\section{Về mặt khoa học}

Đã khảo sát và tối ưu hóa các quy trình phân tích amoni, nitrit, phosphat trong nước biển. Chúng tôi đã khảo sát và đánh giá những ảnh hưởng của một số thành phần và toàn bộ tổng thể nước biển đến toàn bộ quy trình phân tích. Kết quả cho thấy với quy trình chúng tôi đề nghị hoàn toàn không bị ảnh hưởng bởi các thành phần tổng thể nước biển. Kết quả này có ý nghĩa về độ đúng và độ chính xác của quy trình được nâng cao.

Trong phần nghiên cứu thiết kế chế tạo máy quang phổ hấp thu phân tử PNO1 chúng tôi sử dụng những linh kiện điện tử tiên tiến như đèn LED có bước sóng chọn lọc, nhân quang điện (đầu dò) có độ phản hồi và độ tuyến tính cao, bộ hiển thị tích hợp. Đây là lĩnh vực nghiên cứu còn mới mẻ trong nước ta do vậy những linh kiện và thiết bị này hoàn toàn phải nhập ngoại, do vậy kết quả của máy PNO1 còn khiêm tốn, song với yêu cầu phân tích các ion trong nước biển thì máy hoàn toàn có thể đáp ứng tốt về độ đúng và độ chính xác.

Trong phần nghiên cứu chế tạo bộ KIT các hóa chất được pha và dùng với tỉ lệ tiết kiệm nhất do vậy hạn chế được việc thải trở lại môi trường những hóa chất độc hại.

\section{Về mặt thực tiễn}

Hiện nay, các ngành kinh tế biển: dầu khí, khai khoáng, giao thông vận tải, nghề cá, nuôi trồng hải sản, du lịch, nghỉ dưỡng ... đang phát triển rất mạnh và đóng góp trên $45 \%$ GDP của Việt Nam. Bên cạnh những lợi ích kinh tế không thể phủ nhận, các ngành này cũng đang có những tác động xấu đến môi trường biển. Một trong những tác động xấu đó là làm ô nhiễm vùng biển, gây ra hiện tượng phú dưỡng do hàm lượng các muối dinh dưỡng $\mathrm{P}, \mathrm{N}$ vượt quá hàm lượng cho phép. Vì vậy, việc định lượng các muối dinh dưỡng $\mathrm{P}, \mathrm{N}$ là 1 yêu cầu cấp thiết trong công tác đánh giá, bảo vệ và quản lý môi trường biển. 
Hiện nay, các phương pháp phân tích trong phòng thí nghiệm vẫn đóng vai trò tích cực của mình. Tuy nhiên, trong phân tích môi trường, nhất là môi trường biển để đánh giá người ta cần phân tích rất nhiều mẫu, đòi hỏi thiết bị và quy trình phân tích nhanh. Bộ KIT PN01 phân tích nhanh này có những ưu điểm thực tế như:

- Thời gian thực hiện phản ứng nhanh.

- Độ nhạy và khoảng làm việc phù hợp với hàm lượng thấp của các ion nghiên cứu trong nước biển.

- Các thuốc thử được trộn chung với nhau rút ngắn thời gian phân tích.

- Các yếu tố cản nhiễu có hàm lượng thấp nên không gây ảnh hưởng.

- Chi phí cho một mẫu phân tích rất thấp.

Lò̀i cảm ơn: Chúng tôi chân thành cảm ơn Đề Tài KC09-07 đã ủng hộ, khuyến khích và hỗ trợ kinh phí để thực hiện nhiệm vụ nghiên cứu, thiết kế chế tạo thiết bị PN 01 .

\section{TÀI LIỆU THAM KHẢO}

1. Nguyễn Tác An (chủ trì), 2005. Nghiên cứu các giải pháp bảo vệ, phục hồi các hệ sinh thái rạn san hô, cỏ biển và khắc phục ô nhiễm môi trường biển tự sinh. Báo cáo tổng kết đề tài KC 09-07, 248 tr. Thư viện Viện Hải dương học.

2. Fifield FW and Haines PJ, 2000. Environmental Analytical Chemistry, Blackwell Science.

3. Jacobson M., et. al., 2000. Earth System Science, Academic Press.

4. Lenore S. Clesceri, Arnold E. Greenberg, R. Rhodes Trussel, 1999. Standard Methods for the examination of water and wastewater, $17^{\text {th }}$ Edition, American Public Health Assosiation.

5. Richard Clinch J., et. al., 1988. An automated spectromphotometric field monitor for water quality parameters: Determination of ammonia, Analytica Chimica Acta 214, 401-407.

6. TCVN 6663 -14: 2000. Chất lượng nước. Lấy mẫu. Phần 14: Hướng dẫn đảm bảo chất lượng lấy mẫu và xử lý mẫu nước môi trường $25 \operatorname{tr}(\mathrm{A} 4)$.

7. TCVN 6178 - 1996 (ISO 6777 - 1984). Chất lượng nước. Xác định nitrit. Phương pháp trắc phổ hấp thụ phân tử. 
8. TCVN 6202 - 1996. Chất lượng nước. Xác định phốtpho. Phương pháp trắc phổ dùng amoni molipđat.

9. Sven Blomqvist and Susanna Westin, 1998. Interference from chromate, germanate, tungstate and vanadate when determining phosphate in aqueous solution by the phosphoantimonylmolybdenum blue method, Analytica Chimica Acta 358, 245-254.

10. Going J. E. and Eisenreich S. J., 2001. Spectrophotometric studies of reduced molybdoantimonylphosphoric acid, Analytica Chimica Acta 70, 95-106.

11. Drummond L. and Maher W., 1995. Determination of phosphorus in aqueous solution via formation of the phosphoantimonylmolybdenum blue complex. Reexamination of optimum conditions for the analysis of phosphate, Analytica Chimica Acta 302, 69-74.

12. Karl D. M. and Tien G., 1992. Magic: A Sensitive and Precise Method for Measuring Dissolved Phosphorus in Aquatic Environments. Limnology and Oceanography 37, 105-116.

\title{
DEVELOPMENT OF HANDY SPECTROMETER AND CHEMICAL KITS FOR QUICK ASSESSMENT OF SEAWATER QUALITY
}

\section{NGUYEN THANH DUC, NGUYEN MINH TRUC, LE THANH DUNG, VU TRONG HUNG}

\begin{abstract}
Summary: Environmental pollution is a contemporary alert state in Vietnam. One of the reasons is the limit in facility to quickly assess the environmental conditions. A spontaneous assessment in field will help the environmental managers as well as the residents have appropriate solutions to eliminate risks. Our study aims to develop a handy spectrophotometer and chemical kits to determine three nutrient parameters in sea-water including nitrite $\left(\mathrm{NO}_{2}{ }^{-}\right)$, ammonium $\left(\mathrm{NH}_{4}{ }^{+}\right)$and phosphate $\left(\mathrm{PO}_{4}{ }^{3-}\right)$. The testing of this device and chemical kits showed the detection limit $0.38 \mathrm{ppb} \mathrm{NO}_{2}^{-}, 5.8 \mathrm{ppb} \mathrm{NH}_{4}^{+}$and $34 \mathrm{ppb} \mathrm{PO}_{4}^{3-}$. As a first step in our study, we succeeded in manufacturing the handy device and chemical kits which work well in tropical conditions, suitable for field measurement, quality in comparison with imported chemical kits, easy to make, low cost and affordable to widely provide to the community.
\end{abstract}

Ngày nhận bài: 30 - 12 - 2009

Ngườ nhận xét: PGS. TSKH. Nguyễn Tác An 